\title{
La negociación en el proceso conciliatorio
}

\section{Aníbal Sierralta Ríos}

La conciliación es una negociación inducida, ya que son las partes las que deben llegar a un resultado común con la asistencia del conciliador, que tiene como función primordial el facilitar el instrumental técnico para que aquellas puedan, por sí solas, arribar a un acuerdo que solucione sus controversias o posibilite conseguir objetivos comunes.

El proceso conciliatorio y las negociaciones se aplican tanto para resolver conflictos, como para conseguir objetivos comunes cuando existen diferentes formas de solucionar o enfrentar una situación que preocupa a varios individuos, como los casos que afectan a residentes de una población, o cuando se trata de enfrentar la desazón de algunas comunidades ante nuevas construcciones en áreas urbanas en las que los habitantes desean mantener determinados patrones arquitectónicos de valor cultural o sentimental. De tal manera que conocer la técnica y el arte de la negociación se convierte en un desafío permanente para el conciliador y aun para los potenciales usuarios de esta institución o medio alternativo de solución de controversias.

La negociación como manifestación de una actitud humana se desarrolla a través de un proceso. No es una acción espontánea, ni una expresión involuntaria, es un mecanismo con características propias que requiere ser respetado y aplicado ordenadamente para un buen entendimiento de los sujetos.

Debemos considerar dos situaciones claras: las fases a través de las cuales se llega a la negociación, que es connatural a toda comunicación; y el proceso mismo, que involucra las etapas de la negociación y que se deben programar y prever para hacerla más efectiva. 


\section{Marco de la negociación}

La negociación se desarrolla dentro del marco del comportamiento humano, a través de fases que se van sucediendo en el tiempo de manera inmediata, una detrás de otra conformando un todo armónico. Estas fases se articulan entre lo emocional y lo racional que al fin y al cabo es el contenido de la vida misma.

El contacto inicial de dos personas o más está siempre cargado por la emotividad, cuando cada una de ellas pretende agradar, sorprender o impresionar a la otra; posteriormente sobreviene una fase reflexiva cuando los sujetos se plantean los objetivos por los cuales se están reuniendo o expresan el interés de mantener vínculos y las características de cada uno, o admiten la existencia de un conflicto; finalmente, y sólo después, es que se llega al área negocial, en la cual se busca conseguir objetivos compartidos y que las partes de mutuo acuerdo, con el mismo propósito, establezcan líneas de conducta duraderas y provechosas. ${ }^{1}$

Cuando se trata de enfrentar controversias buscando una solución se hace más necesario identificar estas fases, sobre todo la inicial, ya que las partes están bajo una fuerte carga emotiva que les impide ver las posibles soluciones y avizorar las ventajas de un acuerdo estable.

La negociación, pues, transcurre por fases, que podemos graficar como un arco de tres tramos (Gráfico $\mathrm{N}^{\circ} 1$ ) en el que en el primero está representado el área emotiva. En ella los sujetos sólo se mueven en base a impresiones y emociones. Es el tanteo en el que no se pueden establecer líneas de comportamiento ya que los sujetos están alterados por un conflicto o por un daño ocasionado por el otro o por una percepción del negocio que aún no es clara. Este tramo será tanto o más dilatado en razón de la cultura de los individuos. En esta fase no se pueden plantear los aspectos medulares de la negociación, en todo caso, puede servir para identificar a las partes, conocer sus posiciones, el grado de compromiso y el poder que tienen para decidir u obligarse. En esta fase lo que se debe tratar es de crear un ambiente de confianza para que el proceso continúe. Luego, no es recomendable abordar desde un inicio el conflicto mismo o la posible solución.

1 Aníbal Sierralta Ríos. Negociación y Contratación Internacional, Asunción, Universidad Autónoma de Asunción, 1993, p.21. 
La segunda fase es la reflexiva, en la que los sujetos deben entender que su intervención tiene el propósito de generar mutuo provecho y beneficios recíprocos. Aquí es donde los negociadores han de procurar "hacer crecer el pastel" vale decir, buscar no solamente un mayor provecho personal, sino hacer crecer las ventajas y conveniencias para que cada uno vea satisfecha sus pretensiones. En esta fase se ha de buscar identificar los intereses subyacentes.

\section{Gráfico $N^{\circ} 1$}

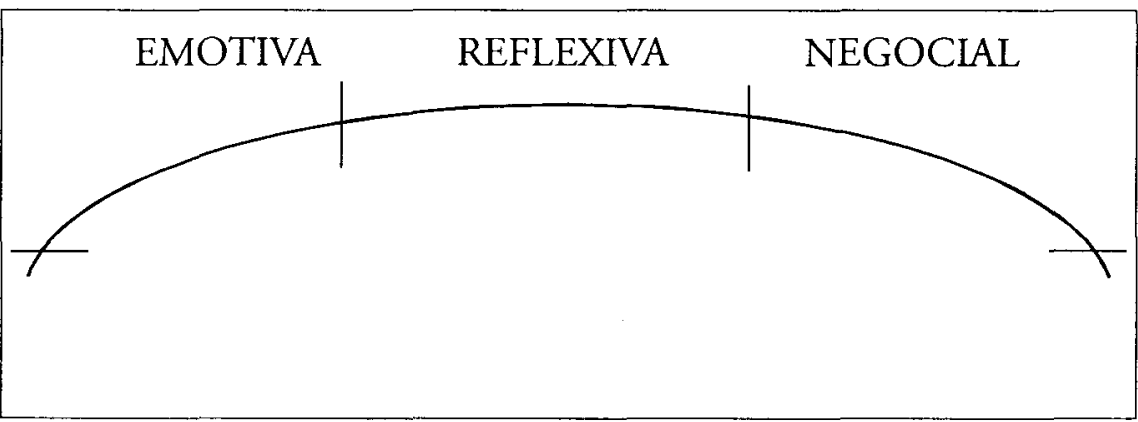

La tercera y última fase es la de la negociación. Es el período en el que se adoptan los acuerdos y las decisiones, después de que los sujetos se han conocido y estiman que justamente los puntos de coincidencia a los cuales llegan son beneficiosos para ambos. En esta última fase hay que reconocer y admitir los intereses y enfrentar el conflicto con visión de futuro. Algunos trabajos sobre el tema consideran que la negociación es un proceso directo al cual se llega solo y en base a las técnicas; sin embargo, la ciencia de las comunicaciones nos enseña a apreciar que hay dos aspectos previos: aquel que ya describimos como emotivo y el que se refiere al entendimiento inteligente de intereses. La negociación pues trascurre por fases que se deben respetar y entender para conseguir un acuerdo duradero.

La negociación es una técnica elevada de comunicación, en la que después de un intercambio de informaciones de las partes se llega a puntos precisos y claros, comprendiendo las distintas percepciones de los sujetos, superando sus términos y desconfianzas y enfrentando hacia futuro la relación sea comercial, vecinal, familiar o financiera. Es la plena comunicación o la confirmación total de un entendimiento o disenso. 


\section{El proceso de negociación}

Muchos sociólogos, administradores de empresas y abogados han apreciado que el proceso de negociación parece progresar hacia una evolución en etapas. Aunque es imposible imponer un modelo de estructura rígido, los negociadores que recién se inician deben cuidar que su comportamiento en este campo sea apropiado para llegar a acuerdos mutuamente compartidos.

El proceso de la negociación es una combinación de tres elementos básicos: objetivos, misión y plan negocial.

\subsection{Objetivos}

Los objetivos están referidos a lo que las partes buscan y anhelan. Lo que se pretende obtener o conseguir en una negociación o lo que se intenta enfrentar. Los mismos que deben establecerse con un mínimo y un máximo, ya que si son cuantificables es mucho más fácil su apreciación (Gráfico $\mathrm{N}^{\circ}$ 2.). Mientras podamos hacer un esfuerzo de establecer los márgenes de nuestros objetivos habremos alcanzado flexibilidad, pues de esa manera las partes pueden articular el proceso dentro de márgenes pre-determinados haciendo más fructífera la relación.

\section{Gráfico $\mathrm{N}^{\circ} 2$}

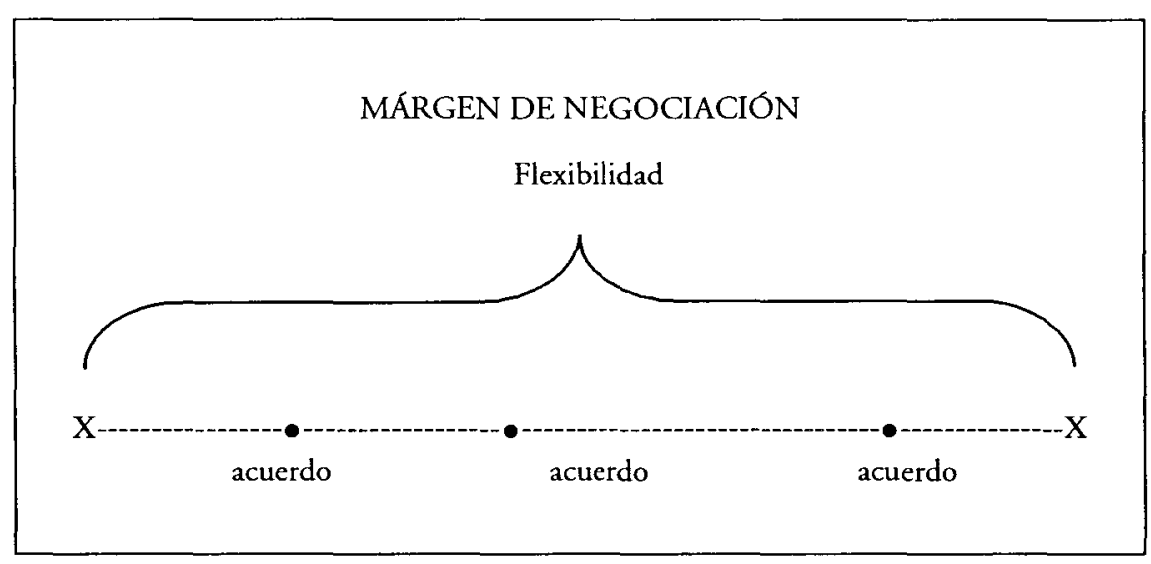




\subsubsection{Determinación de objetivos}

Los objetivos obviamente deben ser reales y han de referirse a lo que se espera conseguir. Su cuantificación, a través del mínimo y máximo será el margen de negociación.

Algunos pensarán que en una compraventa internacional el exportador sólo debe tener presente, en cuanto al precio, un objetivo mínimo y que el máximo es todo aquello que pueda obtener o arrancar del comprador. Sin embargo, esa no es una negociación comercial porque puede ocurrir que hoy, efectivamente, estemos obteniendo la mayor ventaja posible del importador, pero como éste a su vez compra para revender, llegará algún momento a considerar que mantener esos términos de relación comercial son desventajosos y entonces interrumpirá el flujo comercial o, en el peor de los casos, romperá los acuerdos de un contrato porque le será más conveniente incumplir que seguir obligado a aquello que le ocasiona perjuicio.

En los contratos de comercio internacional, el incremento de las ventas es un fin permanente de la relación mercantil, de la misma manera que el importador busca revender a terceros para percibir su margen de lucro que irá in crescendo en cuanto se repita la operación. Es decir, se estará haciendo un mercado. Tal vez el lucro del exportador no se dé en la primera operación sino en las subsiguientes, en tanto que el comprador obtendrá una mayor rentabilidad si la demanda interna de la mercancía se incrementa. Es decir, se estará haciendo crecer ese "pastel hipotético» en el cual tienen interés las partes. Por otro lado, no toda operación mercantil busca un lucro económico inmediato, podría tratarse de una estrategia comercial destinada a abrir nuevos canales de comercialización o desplazar a la competencia de un mercado.

En efecto, en una operación comercial los sujetos parten de un "pastel hipotético» a repartirse buscando obtener la más grande tajada posible. Si ello continúa así, es posible que los sujetos terminen por separarse o hasta entrar en total disentimiento. Sin embargo, si lo que buscamos es más bien repetir el acto y obtener lucros en la medida en que reiteramos la operación, entonces estaremos obteniendo tajadas frecuentes, es decir, «habrá crecido el pastel» (Gráfico $\mathrm{N}^{\circ} 3$ ).

Pero en el caso de una conciliación, también es posible establecer los mínimos y máximos de la negociación. Así, cuando se trate de una pretensión de alimentos, por ejemplo, es posible precisar un minimo y 
un máximo para no alterar la relación con pedidos exhorbitantes sino aquello necesario para el alimentista según su nivel y condiciones. También es viable marcar límites en una acción indemnizatoria, e incluso, en la reparación de daños. Así, los sujetos se pondrán en los zapatos de la otra parte y lograrán precisar razonablemente sus pretensiones.

\section{Gráfico $N^{\circ} 3$}

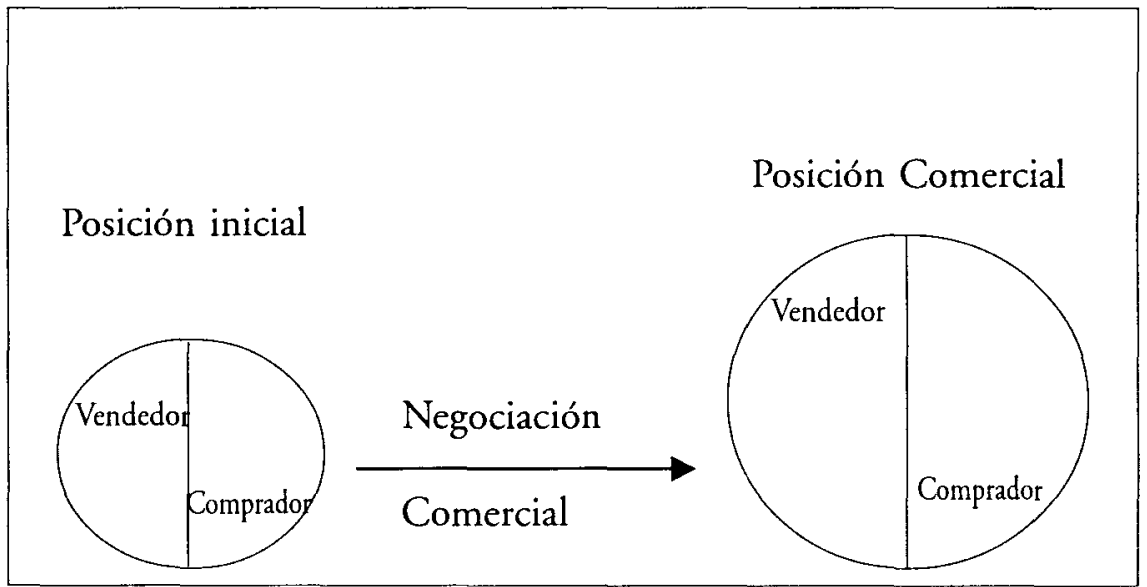

\subsubsection{Las partes en una negociación comercial}

Los objetivos a su vez deben ser priorizados de tal manera que establezcan un orden, sin que ello signifique que en base a esa enumeración deben ser discutidos y resueltos, pues ello dependerá de la vivencia y las circunstancias mismas de la negociación. La relación es para marcar un cuadro de concesiones.

\subsection{La misión}

Es lo que se cree fehacientemente que se puede hacer para convertirse en elemento importante dentro del proceso negociador, así como la apreciación de las alternativas a considerar para llegar a un acuerdo.

La misión es más fácil de observar cuando se trata de cuestiones que involucran a empresas, instituciones o países. En efecto, la misión fre- 
cuentemente revela muchos de los componentes de la estrategia comercial de la empresa o el Estado, lo cual ayuda a explicar porqué éstos hacen lo que hacen de la manera en que lo hacen. La misión es la determinación de los pasos a seguir para el futuro y los cambios que se suscitarán frente a determinados acuerdos o conclusiones.

Revisar los componentes del lineamiento de la misión de la persona, de la empresa o del país debería ser hecho de una manera formal y justa, sobre todo si se trabaja o negocia en equipo. Al revisar todos los elementos que lo conforman, el equipo tiene la oportunidad de observar cómo lo que aprendieron encaja perfectamente en el proceso de negociación. Es importante que el equipo tenga siempre presente su cultura organizacional al analizar $y$, posiblemente, al hacer cambios en el lineamiento de la misión, cuyos componentes varían inevitablemente en tono y estilo.

La misión debe estar plasmada en documentos cuidadosamente elaborados, es importante analizar el propósito de cada frase contemplada en el mismo. Cuando este lineamiento es examinado de dicha manera, será más claro identificar la mayoría, si no todas, las características de la misión que tiene el negociador, la empresa, institución o país, según sea el caso. Así se tendrá en consideración:

- Los valores y cultura

- Los clientes y mercados

- Los productos y servicios

- Los accionistas y directivos

- La tecnología

- La imagen pública

El equipo de negociación debe examinar muy cuidadosamente el lineamiento de la misión institucional, empresarial, o nacional para identificar aquellos puntos que deberían ser modificados o cambiados. Cada punto requiere ser discutido y comprendido en su totalidad, vale decir, desde lo más simple a lo más complejo de su conceptualidad. Durante este ejercicio se escucharán algunas expresiones repetidamente -las cuales deberán ser anotadas por el coordinador del equipo.

La experiencia empírica demuestra que con frecuencia cuando en una organización vertical o en una empresa con jerarquías muy claras se repasan los puntos a tener en cuenta, la palabra "conforme" es cons- 
tantemente repetida durante la discusión. Si posteriormente se utiliza otro concepto o término, como por ejemplo la palabra "flexible» en lugar de la anterior, esta se convertirá en el estribillo y reemplazará a la anterior. Pero si se hace una comparación entre ambas palabras, resultará evidente que el grupo realmente no usa dichas palabras equivalentamente.

La palabra "conforme" es la manera como el grupo responde, para expresar que se está avanzando y se ha entendido, pero no es una muestra que todos admitan lo planteado y de que efectivamente se cumplirá. Cuando se negocia en equipos es conveniente que previamente se coordine entre sus integrantes y se elabore el plan y la agenda. Entonces, cuando los componentes de la misión han sido analizados y el equipo llega a un consenso sobre lo que debe ser planteado en la mesa de negociaciones, unos cuantos miembros deberán ser seleccionados para preparar el bosquejo del mismo, ya que el equipo, como un todo, no siempre puede escribir la versión final. La sabiduría de quienes elaboraron y diseñaron la Declaración de la Independencia de los Estados Unidos de América es un buen modelo de un procedimiento adecuado. A pesar de que en el debate sobre los contenidos de la Declaración de Independencia participaron más de dos docenas de personas, ellos eligieron después de largas discusiones en que se fue diseñando la misión, un comité de tres para elaborarla, dos de los cuales, Benjamin Franklin y John Adams, decidieron que uno de ellos, Thomas Jefferson, prepararía el bosquejo final. De esa manera fue elaborado uno de los más memorables documentos de la historia moderna. Había una misión mutuamente compartida y las ideas fluyeron así claramente redactadas en la Declaración.

Así también ocurre en las empresas y las instituciones. Una persona o máximo dos elaboran el bosquejo e incluso la agenda. Así, una vez que el bosquejo o el borrador esté listo, debe ser analizado nuevamente y mejorado por el equipo y, luego, se debe volver a realizar el borrador final y presentarlo a la organización o a la institución o a la entidad gubernamental antes de iniciar las negociaciones formales.

No es suficiente diseñar la misión; también tiene que ser aceptada. Quienes están envueltos en la creación del credo de la misión deben sentirse identificados y creer en ella. Si la alta gerencia o dirección elabora una misión que no es sino retórica, el equipo no alcanzará sus metas trazadas. Aún cuando la alta gerencia esté ampliamente compro- 
metida, ninguno de los miembros del equipo negociador logrará aceptar o asimilar los esquemas de negociación. Inclusive, puede tomar cierto tiempo antes de que todos puedan hacerlo ya que también deberán modificar sus puntos de vista actuales. Es preciso una buena identificación con los objetivos y con la misión para que el proceso y el esfuerzo sea auténtico. Mientras mayor es la identificación entre los negociadores y la misión, se conseguirá un mayor poder negociador.

\subsection{El plan negocial}

Es el esquema detallado que las partes - y el conciliador en el caso de este proceso- deben diseñar a fin de cumplir con los lineamientos de la misión y de los objetivos. Es el conjunto de acciones destinadas a conocer al otro negociador, el medio ambiente y preparar el momento en que se expondrán las pretensiones y los intereses.

El plan negocial, consiste en la determinación de los pasos a seguir para poner en marcha la misión. El plan es la suma total de metas, factores críticos, suposiciones técnicas y actos del individuo de la organización.

Las etapas básicas de un plan negocial (Gráfico $\mathrm{N}^{\circ} 4$ ), son:

- Margen de negociación

- Lugar

- Apertura

- Exploración e información

- Presentación o aproximación

- Aclaración

- Conclusiones

- Control y evaluación

\subsubsection{Margen de negociación}

La negociación es un ejercicio de concesiones que debe ser calculado antes de su inicio y no durante el proceso. Para hacerlas es necesario primero tener objetivos claros, así como sus mínimos y máximos, ya que la oscilación entre tales extremos posibilitará su intercambio. Las concesiones transcurren a través de esa línea imaginaria entre un míni- 
Gráfico No. 4

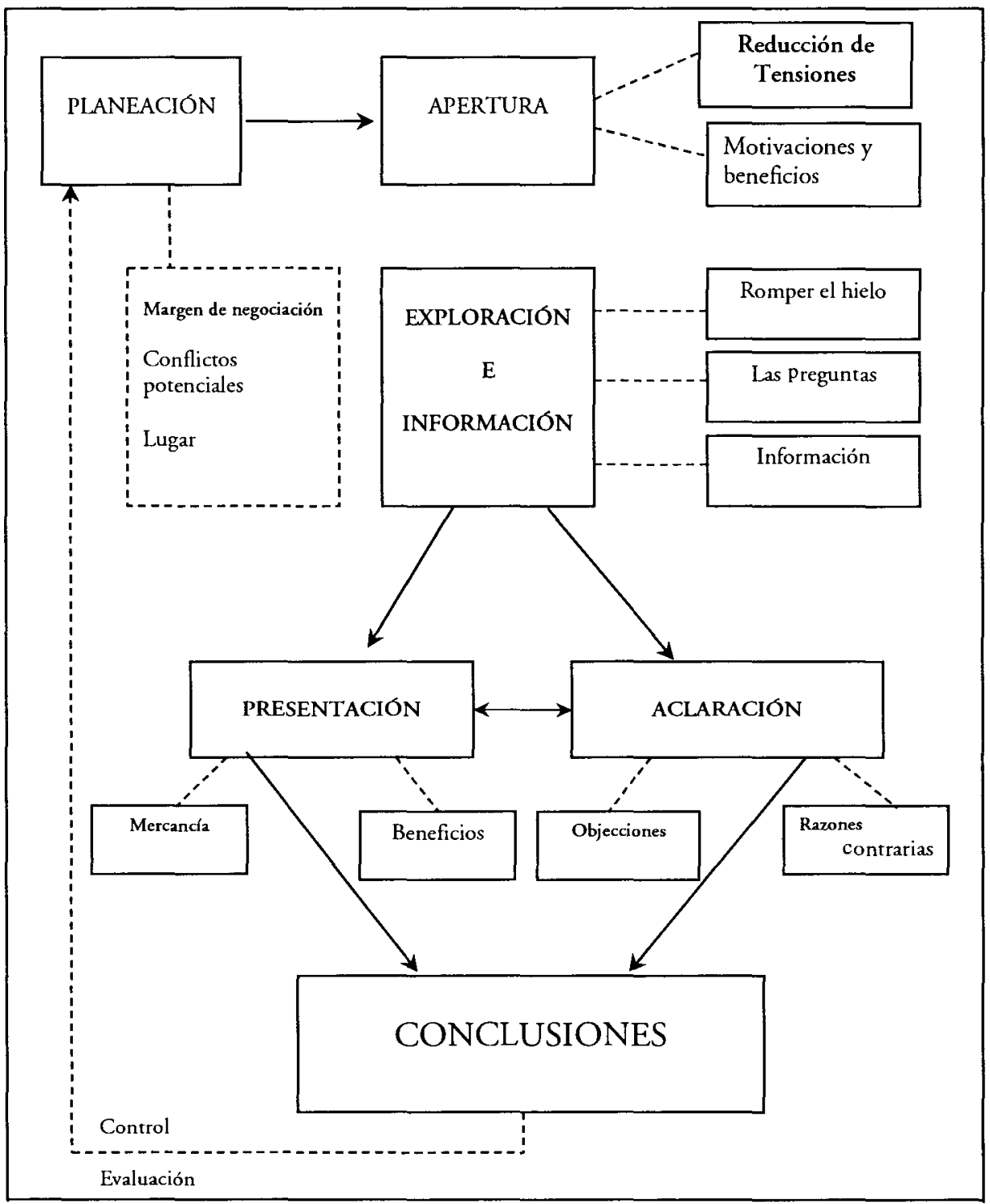


mo y un máximo pues en caso contrario estaríamos abdicando o renunciando de nuestros propios objetivos e intereses.

Es bueno analizar las implicancias de cada concesión y cuáles interesan más o menos a la otra parte. Este último aspecto es crítico, porque lo que no es importante para nosotros puede ser fundamental para el otro.

Lo cierto es que el margen de negociación está dado por la línea imaginaria que une los extremos de cada objetivo, de donde podemos concluir que será buena una negociación en la medida en que lleguemos a acuerdos dentro de esa línea. Será lo que los griegos llamaban el justo medio, es decir el punto medio entre los dos extremos, que no siempre es la mitad o media exacta.

Para oscilar dentro de ese tramo es conveniente tener en cuenta algunas reglas, tales como:

- Precisar muy claramente nuestros objetivos y metas para poder tener la seguridad de una satisfacción dentro de límites pre-establecidos.

- Conocer los objetivos y necesidades de la otra parte y la importancia que tiene para su interés personal, de su empresa, institución o país.

- Colaborar con la contraparte, sin afectar los intereses de nuestra posición. Ello permitirá una relación positiva de negociación que tendrá resultados a veces inesperados y duraderos en el futuro. Así como una experiencia y referencia hacia futuro, ya que las partes pueden encontrarse en una próxima negociación.

- La reciprocidad es una regla común en la vida diplomática y lo es en el de las relaciones de negocios. No en el sentido de que «te doy algo para que tú también lo hagas», sino en el de crear un ambiente propicio. Está más bien referido a una reciprocidad de actitudes, de cortesías, algo así como de «soy educado, así que estimo que la otra parte también lo sea».

- Saber conservar datos y concesiones para el transcurso de la negociación o en otra ronda de operaciones.

No es conveniente agotar todo en la primera parte, es aconsejable guardar provisiones para otras oportunidades.

- Valorizar, si es posible, cada una de las concesiones. Como todo tiene un costo, conviene valorizar las concesiones que se nos otorgan con aquellas que concedamos. 


\subsection{Determinación de lugar}

Es importante definir el lugar o local donde se trabajará. Asimismo, el tiempo o los días y la jornada de cada sesión. De igual manera la agenda o puntos a ser discutidos.

La sala o recinto de una negociación no se puede dejar al azar, incluso el tipo de mesa, influye en la productividad de los operadores. No es lo mismo entablar relaciones comerciales en un ambiente abierto, como en una sala íntima. Las mesas que pueden ser cuadradas, rectangulares, circulares y ovoidales, también deben ser cabalmente escogidas dependiendo del asunto de que se trata. Las mesas semi-ovoides o llamadas sociométricas se estima son las más convenientes, pues permiten el trabajo en equipo y facilitan la integración de los individuos.

En el caso de las conciliaciones es recomendable una mesa, circular u ovoidal a fin de que todas las partes estén sentadas equidistantes, sólo separadas por el conciliador extrajudicial.

\subsubsection{Apertura}

El propósito de esta etapa, que configura el primer contacto entre los negociadores, es la de crear un clima propicio para el desarrollo de la negociación, dejando a las partes cómodas y en libertad para exponer sus puntos de vista.

Un hecho fundamental de las negociaciones, que se olvida con facilidad en las operaciones comerciales y en algunos textos, es que éstas se realizan entre seres humanos y no entre instituciones, compañías o Estados. Ellos tienen emociones, valores profundos, diferentes procedencias, puntos de vista y patrones culturales distintos y a veces son impredecibles. Este aspecto humano es importante en la apertura de esta relación. El proceso que se inicia aquí puede producir un compromiso psicológico tendiente a obtener un resultado mutuamente satisfactorio. Una relación de trabajo en la que a lo largo del tiempo se construyen la confianza, la comprensión, el respeto y la amistad. El deseo de las personas de sentirse satisfechas consigo mismas, y su preocupación por lo que los demás piensan de ellas, puede hacerlas más sensibles a los intereses del otro negociador. ${ }^{2}$

2 Roger Fisher y William Ury. Sí..jde acuerdo!, Bogotá, Normas de Desarrollo General, 1985, p. 23. 
Esta interrelación de deseo, intenciones y aún de incertidumbres, nos lleva a sugerir algunos pasos para hacer efectiva esta apertura y sea en consecuencia un buen preludio al entendimiento mutuo. Estos pasos son necesarios para generar confianza entre las partes y adecuarnos a esa primera fase emotiva de las negociaciones.

Es normal que al iniciar un trabajo conjunto entre personas que antes no se han visto, actúen tensas y se preocupen más por la parte formal, por la apariencia, que por los objetivos y propósitos de la reunión. Se sugiere, entonces:

- Que el negociador muestre interés por su interlocutor, haga preguntas sobre el propio local y ambiente así como por la persona con la cual está hablando.

- Que comente sus aficiones, interés por alguna manifestación del arte, deporte o cualquier expresión del conocimiento.

En algunos casos, hasta es recomendable que las primeras reuniones se realicen en un lugar informal, balneario, hotel o club, a fin de que los sujetos se sientan en la mayor confianza y espontaneidad.

Todo individuo puede estar muy interesado para alcanzar el éxito en una negociación o en los resultados, pero si el proceso o el desarrollo de tal trabajo es difícil y árido quizás ni siquiera intente culminar el proceso y menos que las conclusiones sean de mutuo beneficio.

Las personas buscan siempre ser admitidas y motivadas y ello afecta la cantidad o calidad del rendimiento laboral. Como señala Vinake, la motivación se define como «las condiciones responsables de la variación de la intensidad, calidad y dirección del comportamiento». ${ }^{3}$ Por consiguiente, la motivación está influenciada por valores, sentimientos, hábitos y mecanismos de defensa que se desarrollan a lo largo del tiempo y que guían el comportamiento del negociador.

Hay que tener presente que toda persona actúa dentro de estos lineamientos. Luego, es inconveniente que en una negociación exista un sólo punto de vista de parte de uno de los individuos; o creer que nuestra oferta es razonable y que, en consecuencia, cualquier persona debe aceptarla. Vale decir, tener una sola opción para cada caso.

3 W. E. Vinake "Motivation as a Complex Problem», En: Nebraska Symposium on Motivation, Lincoln, Nebraska, University of Nebraska Press, 1962, p. 3. 
Los obstáculos que a menudo impiden que se de el siguiente paso en la negociación y se camine a la siguiente fase, son los prejuicios y la búsqueda de una sola respuesta.

Todo prejuicio inhibe la imaginación, de la misma manera que los pre-conceptos nos preparan desfavorable o negativamente frente a un negociador. Toda negociación efectiva requiere un pensamiento claro y práctico. Es aconsejable entonces inventar opciones de mutuo beneficio. La imaginación y la invención son un elemento vital y enriquecedor en el proceso de la negociación.

«Si el primer obstáculo para el pensamiento creativo es la crítica prematura, el segundo es la finalización prematura. Si desde el principio se busca la única respuesta mejor, es probable que se esté evitando un proceso de toma de decisiones más prudente, en el cual se seleccione entre un gran número de posibles respuestas». ${ }^{4}$

Toda negociación está sujeta a posibles impases, obstáculos y aún conflictos. La misma relación entre las personas suscita con el tiempo desgaste y situaciones urticantes. El hecho de que dos personas se coloquen frente a frente para tratar un asunto, los lleva sin querer a una especie de competencia. Es como correr deportivamente en un parque y de repente sentir que alguien, haciendo el mismo deporte, se va acercando detrás nuestro, entonces sentimos el impulso de acelerar el paso, para que no nos pasen. Buscamos sin querer la competencia.

Es muy fácil encontrar situaciones en las que los individuos compiten entre sí. En tales circunstancias, la solidez y la moral de las personas es probable que asciendan constantemente a medida que se desarrolla la negociación. Pero las posiciones opuestas entre los sujetos o grupos probablemente degeneren en altercados y hostilidad. En tales situaciones, el mantener o continuar forzadamente con una reunión, en el mismo día, puede, simplemente, agravar el problema. Lo que comienza como un esfuerzo honesto para alcanzar una resolución rápida, puede llegar a ser una demostración pública de la capacidad de cada negociador, para superar a los demás en palabras y en ingenio.5

\footnotetext{
4 Roger Fisher y William Ury. Op., cit., p. 69.

5 Harold J. Leavitt. Psicología Gerencial, Buenos Aires, Contabilidad Moderna, 1970, p. 290.
} 
Los miembros de un equipo negociador se identifican estrechamente con su propio producto o misión y los negociadores se confunden tan solidariamente con sus equipos, que las probabilidades de resolución decrecen a medida que se desarrolla la moral de cada equipo más que a la inversa. Por otra parte, cuando no están identificados con el equipo, los terceros encuentran fácil llegar al acuerdo y calificar algunos de los planteamientos de los grupos como mejores que otros.

Se sugiere, entonces, la mayor comprensión, pues en la medida en que el comportamiento de cada uno es dictado por factores grupales, contribuye a una mayor objetividad. En consecuencia, si de alguna manera podemos identificar los objetivos nuestros con los de los otros quizás se logre una mejor negociación.

La simpatía o antipatía juegan en esto un rol importantísimo. Ya sea la simpatía un proceso de introyección afectiva de una persona en otra, como sostiene Lipps, o una reacción instintiva, como muestra Max Scheler, el hecho es que el fenómeno se da y que se debe tomar en cuenta. El negociador dotado del don de la simpatía expande ese sentimiento en la mesa de reuniones y se puede ganar la voluntad del negociador más duro y reticente. La simpatía es un don valioso, pero peligroso a la vez, según el uso honesto o antisocial que se hace de él, ya que se puede caer en las redes de una contraparte que precisamente usa su simpatía para avanzar en su posición. Por otro lado, la antipatía provoca movimientos de rebeldía y halla grandes dificultades para alcanzar sus objetivos. ${ }^{6}$

\subsubsection{Exploración e información}

Aún cuando esta etapa puede ser considerada dentro de la anteriormente descrita, preferimos separarla para estudiarla independientemente a fin de resaltar la forma en que los sujetos pueden detectar, apreciar y valorar las necesidades, expectativas y las motivaciones que los mueven para llevar a cabo una negociación.

Comúnmente, el negociador empieza presumiendo o prejuzgando las necesidades, carencias o expectativas de la otra parte. Creemos que nuestras propias necesidades son en calidad y porcentaje las mismas 
que las de las demás personas o mayores. La falacia de generalización está casi siempre presente en nuestro análisis lógico.

La persona que está proponiendo algo debe colocarse en la posición y circunstancia del otro sujeto, evitando en lo posible tomar posiciones sobre lo que está diciendo y planteando. Optar por otra conducta es propiciar el enfrentamiento más que la convergencia.

«La negociación basada en posiciones se convierte en un enfrentamiento de voluntades. Cada negociador expone lo que va a hacer o lo que no va a hacer. La tarea de diseñar juntos una solución aceptable tiende a convertirse en una batalla, pues cada parte trata de forzar a la otra a cambiar su posición por medio de pura fuerza de voluntad».?

Como consecuencia de ello, a medida que una parte se ve obligada a ceder ante la cerrada posición de la otra, se va poniendo fría y estéril la negociación. La posibilidad de una ruptura no es de extrañar, ya que el costo de ceder o dejar de lado nuestros objetivos nos llevará a dejar de tener interés en la negociación. Se pierde la motivación y el deseo de obtener o conseguir nuestros objetivos, pues percibimos que nada útil obtendremos porque hay una barrera infranqueable $y$, sobre todo, nuestros planteamientos no son apreciados por la posición rígida de una de las partes.

Para el desenvolvimiento de esta etapa se requiere, entonces:

- Romper el hielo

- Plantear preguntas

- Información y referencias del negociador

- Romper el hielo.

Dejar a la otra parte la oportunidad de exponer sus ideas o planteamientos es siempre buen gesto. Claro está que la mejor forma de que no hayan comentarios es pedir que los hagan, pues las personas se sienten presionadas o acorraladas para hablar y entonces se bloquean. No

7 Roger Fisher y William Ury. $O_{p}$., cit., p.7. 
se trata de pedir directamente que la otra exponga o inicie el trabajo se trata más bien de sugerir, propiciar, motivar.

Algo así como: «me gustaría conocer un poco más sobre su empresa, o su producto", "desearía tener una idea más clara de su ciudad y de la expresión de su oferta exportable" o "me encantaría visitar su país y creo que esta sería una buena oportunidad» o «tengo interés en conocer sus costos generales".

Algunas empresas practican este procedimiento iniciando breves contactos a la hora del desayuno, al recibir a la otra parte en el aeropuerto o tan sólo con una llamada telefónica. Pero no necesariamente debe hacerse en la mesa de las negociaciones. Recordemos que la negociación moderna, el uso de las técnicas y los mecanismos de comunicación, tiene a su disposición una serie de elementos, como el contacto telefónico, el fax, el correo electrónico, el intercambio de folletos, hasta la simple entrega de tarjetas personales es un buen motivo para "quebrar el hielo" y acercar a las personas.

\section{- El uso de las preguntas.}

Este es un mecanismo conveniente para conseguir información que no se puede obtener previamente a través de la inteligencia comercial. Es el dato concreto, más preciso que los catálogos estadísticos y contables. Es saber y conocer la voluntad e interés de los sujetos, incluso determinar los datos sobre los proveedores u otros compradores o vendedores de nuestro ocasional negociador.

También sirve, obviamente, para conocer expresiones comerciales o volumen de producción y aún costos de producción que tal vez no se tuvo tiempo de obtener antes de la reunión de trabajo. Pero, además las preguntas sirven para identificar los intereses subyacentes.

Una de las preguntas más efectivas es la de: «¿Y sí [...]?». Por ejemplo: "yy si comprara $50 \%$ más de mi pedido inicial, cuál sería el precio?» o "¿y si Ud. en lugar de comprar en la posición DEQ, Incoterms 1990 , se traslada a la de CPT, Incoterms 1990, eso afectaría su margen de certeza o seguridad en recibir la mercadería?» Tal vez o siempre pueda conseguir aquello que desea a través de la pregunta "¿Y sí [...]?», pero nueve de cada diez veces la persona con quien se está negociando hará una contrapropuesta en su favor. ${ }^{8}$

\footnotetext{
8 Herb Cohen. Op., cit., p.34.
} 
También es preciso verificar muchos de los términos de una reunión de trabajo, a fin de confirmar si lo que se entendió fue aquello que realmente la otra parte quiso decir. Para ello, se puede hacer preguntas como: «me agradaría ver la posibilidad de que usted pudiera repetirme su planteamiento" o "Ud., podría resumir su punto de vista», o «debo de entender que lo que Ud. ha dicho es [...]”. Con lo que se estará mostrando a la otra parte que somos buenos agentes, que tenemos capacidad de síntesis, y que queremos comprender todo lo que se dice.

Sin embargo, hay que tener cuidado en plantear las preguntas, sobre todo si lo que se quiere es información, ya que un interrogatorio siempre es odioso e incómodo principalmente cuando viene de la esposa. Por ello la mejor pregunta es la que no se hace, a fin de dejar fluir los datos y las precisiones. De tal manera que mejor sería hacer comentarios de situaciones que queremos saber. Contar, referir y relatar situaciones dadas que motiven a la otra parte a añadir su experiencia o situación similar como una forma de retribución comunicativa.

\section{- Información y referencias del negociador}

Por medio de la información comercial, se obtiene una imagen precisa del potencial de un mercado que nos va a permitir trazar las líneas de acción, para elegir un método de distribución y adoptar la organización de ventas y publicidad que dicho mercado exija. Ella debe ser obtenida antes de la negociación para facilitar la articulación de la estrategia y para conocer el medio ambiente en que se desarrollará.

Pero el negociador debe verificar si verdaderamente sigue el camino proyectado y si es viable. Para poder efectuar esta comprobación se debe contar con el feed back del mercado, es decir, una información contínua sobre cómo se pueden desarrollar las ventas, la competencia y el consumo; todo en relación a las expectativas o planes que se tengan. Con tal propósito se debe acumular primero una cantidad determinada de cifras claves. El material debe poder manejarse sin necesidad de un trabajo excesivo, tanto por el que remite la información como por el que la recibe. La información debe iniciarse con el menor número posible de datos, procurando, además, que éstos sean lo más sencillos para que puedan ser manejados por el negociador. ${ }^{\text {? }}$

9 Hans Niklason. Información del mercado (Feedback del mercado), en Venta en los Mercados Extranjeros. Madrid, Ministerio de Economía y Comercio, 1981. pp. 93 y ss. 
Tales datos son obtenidos antes de las primeras reuniones de negociación, en cuyo caso el negociador está más preparado para iniciar el trabajo comercial. Pero aún cuando se cuente con un buen plan de información, algunas cosas sólo podrán ser conocidas en la misma mesa de negociaciones y para ello queda la técnica de las preguntas o los comentarios. La recolección de la información que precede a la negociación, se debe obtener con discreción y determinación. No se debe dar la impresión de ser un policía sino de un hombre de negocios interesado en el tema, o una persona que busca enfrentar un conflicto y resolverlo.

Algunos de los datos que se deben obtener antes o durante las operaciones negociales comerciales son:

- Las condiciones de importación, es decir, los derechos arancelarios, manejo o control de las divisas, licencias de importación, régimen de cuotas o sistemas preferenciales. De igual manera el medio político, social y económico.

- Potencial de ventas o de compras, según sea la posición en que nos encontremos. Aun cuando este es uno de los datos más difíciles de obtener, su conocimiento es importante para saber cómo nos movemos dentro de la línea de mínimo y máximo de nuestros objetivos.

- Sistema de distribución, que incluya las nuevas tendencias que aparezcan, como las integraciones de tipo horizontal (uniones de detallistas) o de tipo vertical (fábricante-mayorista-detallista).

- Comportamiento de la competencia. Aun cuando se sepa quiénes son los competidores dominantes, es bueno saber de primera fuente o a través de nuestra contraparte en la negociación, cuál es su opinión o su experiencia en las relaciones que hubiere tenido con ellos.

Debemos advertir que hay que buscar ideas, conceptos o criterios fundamentales más que descripciones de la situación. Así, es aconsejable indagar por:

- Cartera de pedidos y facturación. Si estamos en la posición de exportador, tenemos que conocer cuál es nuestra situación para obligarnos o no a altos suministros de mercaderías.

- El precio. Tanto los obvios, como son los nuestros, como los de la competencia, sus variaciones y las alteraciones del tipo de cambio. 
- El producto. No solamente las características y el nivel de desarrollo tecnológico, sino el número de reclamaciones que hemos recibido por fallas técnicas o por razones comerciales.

En el caso de las negociaciones orientadas a enfrentar conflictos como es el caso de la conciliación o la mediación es bueno disponer de los siguientes datos básicos:

- Grado de urgencia para enfrentar o solucionar el problema

- Tipos de conflicto que mantiene la otra parte

- Personas involucradas en el conflicto

- Identificación de intereses.

\subsubsection{Presentación o aproximación}

Es el período en que se somete a consideración la propuesta comercial o la posible solución al conflicto, siendo fundamental que ella sea acreditada resaltando la forma en que satisface las necesidades y expectativas de la otra parte, las mismas que fueron detectadas en la etapa de exploración.

Existen formas y frases para iniciar esta etapa, pero una frecuente es empezar diciendo: «[...] considerando los datos y detalles que nos acaba de mencionar, me gustaría sugerir».

En el caso de una operación de venta personal, es decir, el caso de un vendedor en el extranjero como canal de comercialización, deberá tener un gran cuidado, para poder continuar con el plan ya que si se comete un error generará desconfianza. Hay dos aspectos básicos que se deben considerar en este período, los mismos que pueden ser vistos en cualquier orden: la descripción de la mercadería y los beneficios que se espera alcanzar.

La mejor forma de generar confianza es describir el producto o servicio para que se conozca plenamente. Ello significa detallar calidad, volumen y plazo de entrega. Luego se ha de explicar muy claramente cada uno de ellos, enfatizando los que consideramos más importantes.

Las exigencias relativas a conocimientos técnicos dependen de la mercancía que se está negociando. Cuando se trata de bienes de producción, suele ser necesario el contacto con los detalles históricos y costumbres del país en que se está trabajando. 
En el tema de los precios, se debe ser inicialmente genérico para acercar el interés de las partes, a fin de dejar al final su discusión. Y en el caso de las ofertas de instalaciones y maquinarias, es prudente considerar la llamada "cláusula suplementaria de revisión de precios».

Después de ello, hay que dar paso a la apreciación de los beneficios que esperan obtener los individuos o negociadores.

Los beneficios o las necesidades que son satisfechas con un producto o servicio, deben ser suficientemente resaltadas. Se deben considerar únicamente los beneficios ya identificados en la etapa de exploración. Es aconsejable no presumir nada, ya que algunas cosas pueden ser importantes para uno pero no para el resto.

Claro está que si podemos cuantificar los beneficios, esto será mejor para que la otra parte entienda claramente las ventajas de concretar la negociación a través de un contrato o un acuerdo final.

\subsubsection{Aclaración}

Por más ilustrativa que sea la presentación es posible que queden algunas dudas. Luego, es conveniente aclararlas, para saber si los sujetos están en la misma inteligencia. Es el feed-back de todo proceso de comunicación.

El sentido que le damos al término feed-back difiere de la idea popular. Para el caso, es la respuesta, realimentación, regeneración. Es la capacidad del hombre -y de algunas máquinas según el estudio de Norbert Wiener (Cybernetics) - para detectar cualquier error o desviación que se produzca en el transcurso de la negociación y para aclararlo a fin de que se entienda en el mismo sentido que las partes quieren expresarlo. Es el circuito que explica la comunicación y por el que circula un flujo continuo de información entre el sistema, sus partes y el entorno.

«Así que todos necesitamos basarnos en las respuestas para apreciar la claridad de nuestras comunicaciones".

"Así es como debe ser. Pero al recibir e interpretar esas respuestas debemos analizarlas, precisar su exactitud y no aceptarlas a carga cerrada y sin la conveniente crítica».

"Si tenemos presente que puede fallar nuestro mensaje por múltiples causas, veremos la necesidad de idear todos los métodos 
posibles para asegurar la adecuada réplica y para convencernos plenamente de que logramos darnos a entender sin ambiguedades, oscuridades o tergiversaciones». ${ }^{10}$

En esta etapa es conveniente tener en consideración la necesidad de absolver algunas objeciones o aceptar las razones contrarias.

Toda persona frecuentemente tiene más objeciones que confirmaciones, por lo que no debemos sorprendernos cuando éstas se presenten. La primera regla para este caso es mantener la calma. Hay que dejar que ésta se exponga de la manera más extensa posible. Debe procurarse no caer en un asunto personal ni asumir posiciones intransigentes.

Las razones frecuentes para las objeciones son el miedo a cometer errores, falta de confianza, información insuficiente, o distintas prioridades. Lo importante es tener argumentos para rebatirlas.

Hay que evitar frases que puedan generar conflictos como: «no me entendió nada", o, "está totalmente equivocado».

Por otro lado también hay que entender las razones contrarias aunque se busque el mismo común interés. En efecto, aun cuando comprador y vendedor tiene un interés común -realizar negocios- ambos están en posiciones distintas y, como se ha dicho, han llegado a la mesa de negociaciones posiblemente por diferentes motivaciones.

Algunos presentan razones contrarias en base a la lógica o a situaciones objetivas, pero otros en base al sentimiento, al impulso. Hay que reconocer que las personas pueden tener diferentes puntos de vista sobre el mismo asunto, pero que ello no nos aleja de la razón principal que nos puede convocar: realizar una negociación cuyos resultados sean estables y duraderos.

\subsubsection{Conclusiones}

En realidad, esta es la etapa final de la negociación, pues aquí se ven los resultados a través de los puntos de coincidencia y aún de disentimiento, si se está de acuerdo en ello. Aquí es donde se puede decir que está "cerrado el negocio». Ya no hay nada más que decir, la palabra está

10 Norman B.Sigband. Comunicación para Directivos. Salamanca, Ed. Anaya, 1971, p.29. 
empeñada y existe el pleno compromiso de ejecutar los términos del acuerdo (el contrato).

Si todo el proceso de negociación se ha llevado bajo una adecuada metodología, como la que se está proponiendo, las conclusiones deben fluir por sí solas, pues en realidad éstas se han ido esbozando en cada una de las etapas. Este es el colofón de la negociación de la conciliación.

En algunas circunstancias es aconsejable recapitular los beneficios que va a traer esta relación de negocios. La única novedad que surge en esta fase es la fecha en que se suscribirá el contrato o el acuerdo. Nadie busca redactar un contrato si éste no es solicitado.

\subsubsection{Control y evaluación}

El control sirve para identificar en qué etapa del proceso de negociación existe una deficiencia y formular posteriormente las recomendaciones que sean necesarias.

La profesionalización del negociador exige no solamente tener una metodología sino, además, conocer los errores, faltas u omisiones para corregirlos o superarlas en el futuro, requiriendo para ello una vigilancia acuciosa y regular. Por lo demás, como las operaciones y modalidades comerciales han crecido y son cada vez más variadas, existe mayor cantidad de asuntos que controlar y evaluar. No obstante, el negociador, en un mundo bombardeado por informaciones y referencias estadísticas, se ve precisado a prestar atención a los datos y las cantidades y a obtener perspectivas de diagnósticos, en vez de controlar el proceso de negociación.

Cuando tal problema se presenta, ello puede deberse a que el plan y el proceso de negociación es incorrecto, en el sentido de que no se ajusta al medio en el cual se desenvuelve el trabajo comercial, o que el plan es correcto pero se ha ejecutado inadecuadamente.

«El control es un procedimiento conciente que mediante la utilización de un monitor permite detectar cambios en los estados de naturaleza, con el propósito de encontrar diferencias significativas entre hechos reales y planeados, a fin de hacer apropiados ajustes al curso de acción que debe seguirse»" ${ }^{11}$.

11 Héctor Mario Bogo. Decisiones en Comercialización. Buenos Aires, Ed.Macchi-López, 1975. p. 467. 
Las técnicas de control ayudan a definir el problema práctico con claridad y apreciar las acciones que se deben tomar. Sin embargo, pocas personas desenvuelven esta última etapa de la negociación. El negociador, de manera analítica, debe plantearse al final de cada experiencia los términos y condiciones en que se inició el trabajo y aquellos en que fueron concluidos. De igual forma los plazos, costos, condiciones, así como las acciones que se deben tomar para implementar lo que fue negociado.

La evaluación de la negociación requiere, como cosa ideal, un raciocinio que explique la forma en que funciona el proceso, incorpore críticas válidas y genere criterios sobre los que puede emprenderse alguna acción. Para ayudarnos a evaluar una cosa tan sutil y al mismo tiempo compleja como es la relación entre personas, es menester acudir al marco antropológico de las relaciones y el comportamiento humano dentro del cual vive toda interrelación humana. A fin de facilitar esta evaluación, sugerimos se compare lo previsto con lo logrado en la negociación, se analicen las concesiones, sus consecuencias y cómo fueron recibidas por la otra parte; finalmente, las recomendaciones para futuros encuentros.

\section{El proceso conciliatorio}

En la conciliación las partes son las que negocian directamente, pero en la mayoría de los casos no tienen una preparación o formación previa. $\mathrm{El}$ procedimiento se inicia con la solicitud de la pretensión al Centro de Conciliación y la posterior designación del conciliador, quedando en manos de éste la orientación y asistencia de las técnicas de negociación a las partes en conflicto.

El conciliador actúa como impulsador del acuerdo pero también desarrolla una tarea pedagógica para que las partes alcancen sus objetivos, así como para evitar el desequilibrio por el poder de alguna de ellas. Siendo que la información o el conocimiento que de la negociación tenga alguna de las partes en desmedro de la otra ya es una expresión de asimetría; ésta será mayor si cuenta con la asistencia de un especialista con experiencia. Debe igualmente estimular que los sujetos salgan de determinadas posiciones rígidas facilitando la discusión creativa e imaginativa por encima de la discusión dialéctica. A partir de enton- 
ces y reconociendo las tres fases a través de las cuales se desarrolla toda negociación (emotiva-reflexiva-negocial), se deben articular las sesiones de la audiencia única en que se desenvuelve el proceso conciliatorio. De esa manera, tendríamos tres sesiones bien definidas: la primera destinada a generar confranza (sesión conjunta inicial); la segunda a identificar los intereses subyacentes (sesiones privadas) y la tercera $y$ última a propiciar la convergencia (sesión conjunta final).

\subsection{Sesión conjunta inicial}

Usualmente las partes llegan a la conciliación bajo una fuerte carga emotiva y gran desconfianza, pues cada una de ellas percibe que su derecho ha sido preterido o conculcado. Para que el procedimiento se desarrolle, es necesario que las partes tengan confianza en el proceso, en el conciliador y empiecen a entenderse entre ellas. En definitiva, generar un ambiente de confianza que es el clima fundamental para la conciliación.

Esta sesión conjunta inicial sirve para la ilustración del proceso a cada una de las partes. El conciliador deberá dejar expresa constancia de las sesiones que se llevarán a cabo, señalando día y hora en que continuarán.

Aunque el Inc. 4 del Art.17o del Reglamento de la Ley de Conciliación peruana señala que en la primera sesión, "el conciliador debe promover el diálogo y eventualmente proponerles fórmulas conciliatorias no obligatorias", estimamos que en esta primera sesión, sólo debe concretarse a promover el diálogo y tratar de articular la negociación para crear un ambiente de confianza, dejando para las siguientes sesiones o la última (conjunta final) la proposición de fórmulas de acuerdo, pues son los sujetos en conflicto los que deben articular el acuerdo y diseñarlo para que sientan el deseo de mantenerlo y cumplirlo. La propuesta por el lado del conciliador debe ser una última consideración y sólo después de haberse agotado el esfuerzo de los conciliantes.

La intención de la primera sesión es que las partes reconozcan la existencia de un conflicto y se comprometan activamente en un proceso diseñado para solucionarlo, pues no siempre los partícipes admiten que son parte del problema. De esa manera el esfuerzo de esta primera sesión ha de circunscribirse a crear un ambiente de confianza y admitir que hay un conflicto que los involucra. De allí en adelante se pondrán 
de acuerdo en el procedimiento y el ámbito apropiado para que ello se lleve a cabo, ya que no hay que olvidar que este es un mecanismo autocompositivo y, entonces, las partes han de elaborar su procedimiento.

En esta primera sesión se indicarán las reglas básicas y pautas de comportamiento para evitar un crecimiento del conflicto o la controversia. Las partes no siempre son adversarias ya que puede tratarse de percepciones diferentes, e incluso si lo son, no tienen porque serlo para siempre. Así que hay que cuidar que el tratamiento y la exposición de las ideas coadyuven a la solución de la controversia antes que a su complicación.

También hay que conseguir el primer pre-acuerdo: el de la confidencialidad. Las disputas se resuelven mejor conservando un ámbito de privacidad y la mayoría de las personas prefieren arreglar sus asuntos dentro de los límites de su área de acción.

Hay que recibir las posiciones de cada una de las partes, sin ningún comentario ni calificación aunque después, en el transcurso del proceso, se cambien o modifiquen ya que la legislación peruana lo permite, siguiendo el razonamiento y técnica de la conciliación y la mediación. Todo lo que el conciliador puede hacer es una síntesis de cada una de ellas para mejor conocimiento de los partícipes.

Un conciliador carece de poder de decisión autorizado. Esta característica distingue al conciliador del juez o el arbitro, designado por la ley o por un contrato para adoptar una decisión acerca de las partes sobre la base de normas sociales, leyes o contratos, más que de los intereses específicos o los conceptos personales de justicia afirmados por las partes. ${ }^{12}$

Después de conocer las posiciones y haber creado un ambiente de confianza es que se podrá continuar con el proceso, pasando a sesiones privadas.

\subsection{Sesiones privadas.}

El conciliador invitará por separado, en número similar de sesiones, a cada una de las partes para identificar los intereses subyacentes y para

12 Christopher W. Moore. El Proceso de mediación, Buenos Aires, Gránica S. A. , 1995, p.49. 
intentar fórmulas de acuerdo con vista al futuro y con carácter de permanentes.

El conciliador indagará sobre los puntos de vista de las partes y cualquier otra información que se estime relevante al problema. Asistirá e ilustrará en las técnicas de la negociación.

Es posible que los participantes tengan una información previa sobre las posiciones, posibilidades y limitaciones de la otra parte y ello se convierta en una ventaja para articular la negociación, configurándose un desequilibrio de poder.

En esa situación el conciliador debe asegurarse que toda información sea compartida por todos los intervinientes, de modo que los datos, cifras y referencias serán verificados e intercambiados.

En estas sesiones los sujetos clasificarán los temas y asuntos a negociar y a conocer cuáles son las posiciones e intereses de cada uno de ellos. Es común que hayan pensado muy poco acerca de lo que cada uno desea o quiere, ya que están concentrados en su percepción y en elaborar su argumentación para dominar a la otra parte. Cada uno cree que tiene la razón y en consecuencia busca defenderla. Si se mantiene esta actitud es difícil arribar a un acuerdo. Se aconseja al respecto hacer un ejercicio de desdoblamiento. Colocarse en la posición contraria, es decir "ponerse en los zapatos del otro" ayuda a entender a los demás. Así, porqué no pensar en un instante cuál sería nuestro papel y conducta si fuéramos una madre que busca alimentos a la prole; o cómo se sienten los deudos cuando han visto que un automóvil lujoso ha cegado la vida de un modesto padre de familia sin seguro y la parte actora solo quiere reconocer como indemnización al 10\% o $20 \%$ del valor del vehículo que instrumentalizó el daño.

En estas sesiones es donde es posible proponer algunos proyectos de acuerdo, cuando ya se han mostrado los intereses subyacentes.

También ha de identificarse las metas que deben satisfacerse en un posible acuerdo. Identificar las aristas y características del conflicto que posibilitan ayudar a los litigantes a alcanzar sus objetivos individuales, gremiales o asociativos.

El conciliador es un especialista que reuniéndose separadamente con cada una de las partes y sus asesores -si se ha convenido la intervención de ellos- las inducirá a examinar e identificar sus propios intereses y las de las otras partes. A partir de entonces se podrán seleccionar los intereses mutuamente compatibles y los incompatibles, las formas de po- 
der real o potencial de los sujetos actuantes, la antigüedad del conflicto y las personas que están involucradas en él.

Cuando se trata de conflictos vecinales, como por ejemplo, la ocupación de zonas comunes (jardines, zonas de recreo y los pasos entre las viviendas) o cuando el conflicto involucra al grupo familiar, es recomendable que participen en estas sesiones toda la familia, no solo los padres, sino los abuelos y los hijos, para comprender la magnitud de la colisión de intereses, así como para compartir las propuestas de acuerdo. En la experiencia argentina es frecuente que en situaciones similares participen no solo los jefes de familia, sino todos los afectados. Ello ha dado buenos resultados pues se han llegado a acuerdos duraderos y satisfactoriamente admitidos por las partes.

El colofón de estas sesiones será evaluar los resultados potenciales o probables del conflicto.

\subsection{Sesión conjunta final}

El propósito de este último período es el de precisar los extremos del acuerdo y la forma en que se cumplirá, en el entendido que satisfacerá a todas las partes.

$\mathrm{El}$ acuerdo ha de ser viable, operativo y de ejecución inmediata. Ha de contener el procedimiento para hacerlo factible y realizable.

El conciliador redactará el acuerdo final indicando los parciales o la forma en que se ha fraccionado el convenio marco o mecanismo de compromiso. Debe ser redactado en un lenguaje sencillo, coloquial que sea entendido por cualquiera de las partes, sin la necesidad de asistencia legal o de sus asesores, excepto cuando se trate de cuestiones jurídicas ejecutables en las entidades de la administración pública, como en el caso de los registros de propiedad, los municipios o las diferentes entidades del Estado, en que habrá que acudir al abogado del Centro de Conciliación o a los abogados de las partes para redactar el acuerdo en lenguaje jurídico.

El acuerdo debe estar expresado en el Acta (Art.16 $6^{\circ}$ del Reglamento de la Ley de Conciliación peruana) la cual debe contener: lugar y fecha, nombres, identificación y domicilio de las partes, nombre e identificación del conciliador, descripción de las controversias, firma y huella de todos los que participen y el nombre y firma del abogado del Centro de Conciliación. 